\title{
INTEGRATED TOFU MACHINE UNTUK PENINGKATAN PRODUKTIVITAS PRODUSEN TAHU SARI RASA DESA SINDANG SARI KECAMATAN CILEUNYI KABUPATEN BANDUNG
}

\author{
Mulyana, C., Saad, A.H. dan Nurhilal, O. \\ Departemen Fisika, Fakultas Matematika dan Ilmu Pengetahuan Alam Universitas Padjadjaran \\ E-mail: c.mulyana@yahoo.com
}

\begin{abstract}
ABSTRAK
Mesin pembuat tahu otomatis atau ATM-Machine (Automatic Tofu Maker-Machine) ini meruapakan salah satu upaya penerapan teknologi tepat guna, untuk memecahkan permasalahan mitra pabrik tahu Sari Rasa yang terletak di Desa Sindang Sari, Kecamatan Cileunyi, Bandung, Jawa Barat yang selama ini masih menerapkan cara tradisional dalam proses pembuatan tahu. Cara tradisional pembuatan tahu terdiri dari enam tahapan yaitu penggilingan kedelai, perebusan bubur kedelai, penyaringan untuk mendapatkan sari kedelai, pembibitan (penambahan asam cuka), pencetakan, dan pewarnaan, masing-masing proses tersebut dilakukan secara terpisah dan manual. Dengan ATM-Machine proses penggilingan kedelai, perebusan bubur kedelai, penyaringan bubur kedelai, dan pembibitan susu kedelai bias dilakukan dalam satu rangkaian proses. Dibandingkan dengan proses produksi tahu secara tradisional ATM-Machine memiliki beberapa keunggulan, antara lain waktu produksi yang lebih singkat, lebih higienis, bisa dioperasikan hanya oleh satu orang, dan membutuhkan lahan yang lebih kecil. Poin positif lainnya adalah system pemanas tradisional digantikan dengan sistem pemanas boiler yang dapat mereduksi kebutuhan bahan bakar, dan tingkat efisiensi boiler adalah $70 \%$ hingga $90 \%$. ATM ini telah disosialisasikan dan di implementasikan kepada pembuat tahu berskala kecil di Desa Sindang Sari Kecamatan Cileunyi Kabupaten Bandung. Kehadiran ATM disambut baik oleh pengrajin tahu karena dapat meningkatkan produktivitas dan menghemat biaya produksi.
\end{abstract}

Key words: Mesin tahuo tomatis, reduksi langkah kerja, higienitas, lebih efisien.

\section{ABSTRACT}

Automatic Tofu Maker or ATM-Machine (Automatic Tofu Maker-machine) is applied technology to solve problem for traditional tofu factory named Sari Rasa, located in Sindang Sari, Cileunyi, Bandung, West Java.Tofu maker traditionally, producing tofu consist of sixsteps :milling, boiling, filtering, coagulating, pressing, and colouring. Each step is done separately, by manual operation. With this ATM-Machine, those six steps of producing tofu could be done automatically in a consecutive process. The four process milling, boiling, filtering, and coagulating combine in one process. Compare with traditional one, this ATMMachine have some advantageous. The production time is shorter, more hygiene, can be operated by one person, and the space used is smaller. Another positive point, traditional boiling systems substituted by used boiler which the fuel needed reduced, and the efficiency of the boiler is between $70 \%$ to $90 \%$.

The ATM has been socialized and implemented in Sari Rasa Tofu Factory located in Cileunyi, Sindang Sari village, Bandung Province. The factory owner very appreciated to the Integrated Tofu Maker because its improve productivity and reduce production cost.

Keywords: Automatic Tofu Maker Machine, reducing steps, hygiene, more efficiency

\section{PENDAHULUAN}

Industri produksi tahu memang cukup berkembang dan tersebar di seluruh Indonesia. Rata-rata pelaku industri produksi tahu adalah industri menengah ke bawah, sedangkan pabrik tahu dengan skala besar masih jarang ditemukan. Dalam proses produksinya, mitra kerja pabrik tahu Sari Rasa yang terletak di Desa Sindang Sari memanfaatkan teknologi manual dan dikerjakan melalui serangkaian akitivitas yang terpisahpisah sehingga memakan waktu yang cukup lama. Efisiensi waktu, tempat, dan tingkat kebersihan yang buruk yang menjadi masalah utama bagi pabrik tahu Sari Rasa.

Untuk membantu mitra memecahkan permasalahan tersebut dibuatlah suatu mesin pembuat tahu otomatis yang bekerja dengan prinsip penyatuan keempat tahapan produksi yang pertama yaitu penggilingan, perebusan, penyaringan, dan pembibitan. Untuk meningkatkan efisiensiproses serta laju produksipersatuan waktu, mesin dirancang untuk proses pembuatan tahu secara mekanik agar bisa menggabungkan keempat tahapan proses dalam sebuah peralatan/mesin.

\section{BAHAN DAN METODE}

a. Permasalahan mitra

Mitra memerlukan sebuah mesin yang dapat mempercepat proses produksi, mengurangi jumlah tenaga kerja yang dibutuhkan, menghemat energi, meningkatkan kualitas kebersihan produk, meningkatkan jaminan keselamatan pekerja, mesin tidak memakan tempat yang luas.

b. Persiapan

Pada tahap persiapan dilakukan wawancara mengenai permasalahan-permasalahan yang di hadapi mitra selama proses produksi berlangsung, antara lain: kesulitan mencari tenaga kerja, tingkat kebersihan produk yang buruk, proses produksi memerlukan waktu yang lama, memerlukan lahan yang luas untuk penempatan alat-alat produksi, terdapat risiko terjadinya kecelakaan kerja terutama saat proses penyaringan sari tahu.

c. Desain alat

Untuk memecahkan permasalahan-permasalahan yang dihadapi mitra, dirancanglah sebuah alat yang bernama ATM-Machine dengan design sebagai berikut:

d. Pembuatan alat Pembuatan alat dilakukan di PT.Bumi Braja Nusantara yang terletak di LIK (lingkungan industry kecil) 

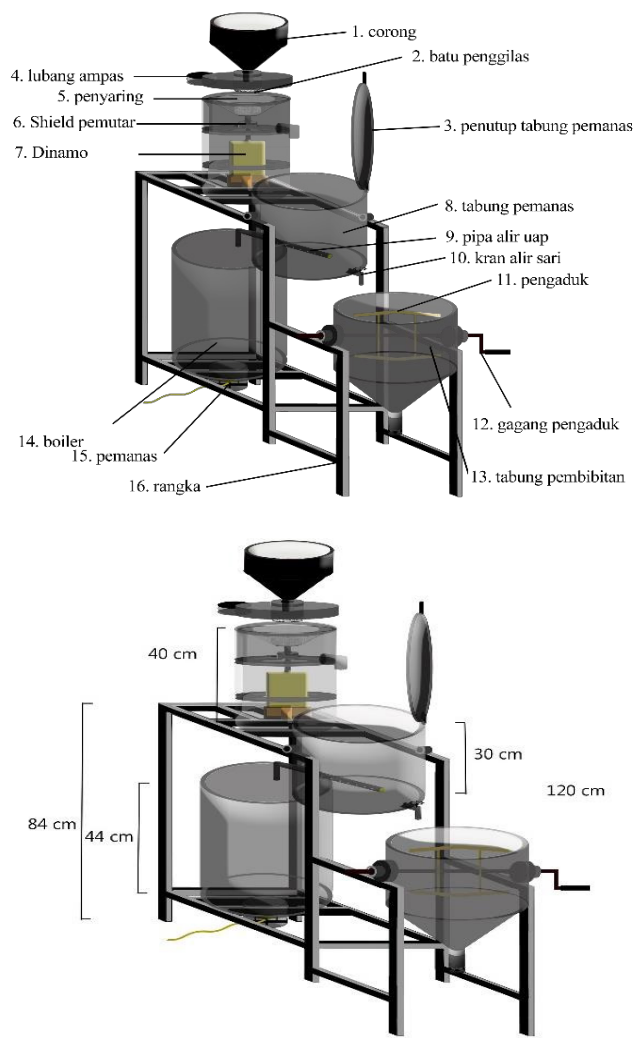

Gambar 1. Design Tate grated tofu mechine

Gede Bage, Bandung Jawa Barat. Proses pembuatan alat meliputi perancangan design mekanik alat, penentuan jenis material, dan implementasi rancangan alat.

e. Sebelum dilakukan uji coba pada mitra pabrik tahu Sari Rasa, terlebih dahulu dilakukan uji coba alat di PT. Bumi Braja Nusantara, dan

f. Untuk mengetahui kenerja alat saat dilapangan maka dilakukan uji coba dan instalasi alat pada mitra pabrik tahu Sari Rasa Desa Sindang Sari.

\section{HASIL DAN PEMBAHASAN}

Dihasilkannya mesin yang dinamai dengan ATMMachine. menjawab permasalahan-permasalahan yang muncul selama proses produksi berlangsung, antara lain: a. ATM-Machine dirancang untuk membantu mitra pabrik tahu Sari Rasa untuk memecahkan permasalahanpermasalahan yang dihadapi selama proses produksi berlangsung.

b. ATM-Machine pada pabrik tahu Sari Rasa. ATMMachine selanjutnya dicocokan pada mitra pabrik tahu Sari Rasa.

c. SetelahATM-Machine diuji cobakan, mitra merasa puas karena ATM-Machine dapat mengatasi permasalahanpermasalahan yang dihadapi selama proses produksi berlangsung, antara lain :

1. lahan pabrik yang lebih kecil Dimensi dari ATMMachine adalah sebagai berikut, Tinggi ATMMachine adalah $2 \mathrm{~m}$, lebar $0.65 \mathrm{~m}$ dan panjang $0.9 \mathrm{~m}$, sedangkan pada mitra pabrik tahu Sari Rasa membutuhkan luas lahan dengan panjang $16 \mathrm{~m}$ dan lebar $8 \mathrm{~m}$ untuk penempatan alat-alat produksinya, sehingga ATM-Machine dapat memperkecil kebutuhan lahan yang diperlukan.

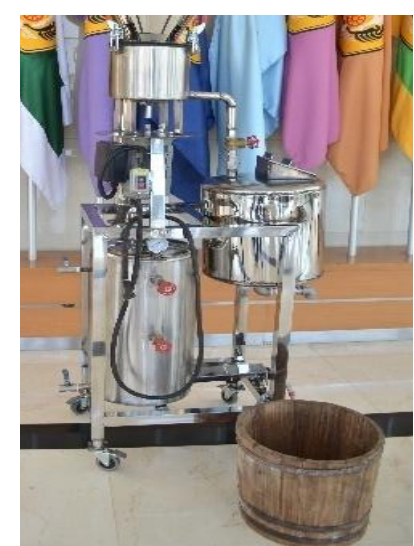

Gambar 2. ATM Mechin

2. Keselamatan pekerja, pada proses pembuatan tahu di pabrik tahu Sari Rasa proses penyaringan tangan pekerja seringkali bersentuhan dengan cairan panas secara langsung, dan berdasarkan pernyataan dari bapak Yana yang bekerja pada proses penyaringan kedelai hanya mampu bertahan paling lama satu minggu. Pada ATM-Machine proses penyaringan, dan pemanasan dilakukan secara otomatis dengan bantuan alat sehingga cairan tahu yang panas dapat dikondisikan agar tidak bersentuhan dengan tangan sehingga lebih dapat menjaga keselamatan pekerja.

3. Daya tahan produk. Pada mitra apabrik tahu Sari Rasa sistem pemanas menggunakan tungku api dengan bahan bakar LPG (Liquefied Petroleum Gas)

4. Laju produksi. Berdasarkan hasil uji coba laju produksi per satuan waktu berjalan secara lebih cepat yaitu $2 \mathrm{~kg} / 10$ menit sedangkan dengan menggunakan sistem manual laju produksi adalah $2 \mathrm{~kg} / 20$ menit.

5. Efisiensi bahan bakar. Penggunaan boiler sebagai pemanas berdampak pada Penghematan bahan bakar. Dengan menggunakan boiler, uap panas dapat disalurkan dari satu sumber ke beberapa tabung pamanas sehingga apabila akan ditambahkan jumlah tabung pemanas pada ATM-Machine, jumlah bahan bakar yang dibutuhkan masih tetap sama.Selain itu tingkat efisiensi dari boiler adalah 70\% hingga $90 \%$, hal ini lebih tinggi jika dibandingkan dengan tingkat efisiensi kompor bisa dengan tingkat efisiensi berkisar 30\%.

6. Tenaga kerja. Untuk menjalankan ATM-Machine hanya memerlukan satu orang pekerja sedangkan pada sistem manual membutuhkan minimal enam orang pekerja agar proses produksi bias berjalan maksimal.

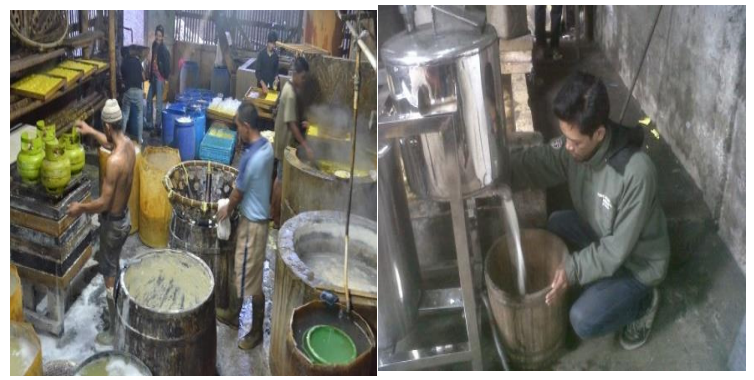

Gambar 3. Proses Pembuatan tahu Konvensional - ITM 


\section{SIMPULAN}

melalui kegiatan PPM Prioritas telah dihasilkan ATM-Machine; terimplementasikan alat pada pabrik tahu Sari Rasa; dilakukan pada pabrik tahu Sari Rasa Desa Sindang Sari dan mitra puas akan hasilnya selain itu, ATM-Machine dapat mengatasi permasalahanpermasalahan yang dihadapi selama proses produksi berlangsung.

\section{UCAPAN TERIMA KASIH}

Dengan terselesaikannya karya tulis ini, penulis mengucapkan terimakasih kepada:

1. Direktorat Jenderal Pendidikan Tinggi sebagai penyelenggara kegiatan Program PPM Prioritas.
2. Universitas Padjadjaran sebagai pendukung utama dalam setiap tahapan kegiatan Program PPM Prioritas.

3. Pabrik Tahu Sari Rasa sebagai mitra kerja yang telah membantu penyelesaian Program PPM Prioritas ini hingga dapat terlaksana.

4. PT. Bumi Braja Nusantara sebagai partner kerja tim dalam proses pembuatan alat/mesin.

\section{DAFTAR PUSTAKA}

Asmudi, 2010 . Analisa unjuk kerja boiler terhadap penurunan daya pada PLTU PT.Indonesia power ubp perak. $1(1): 3$

R. I. DepartemenPertanian, 2013 .Buletin Konsumsi Pangan. Edisi ke-4. Jakarta. Indonesia 